\title{
Professores de Ensino Superior da área da Saúde e sua prática pedagógica
}
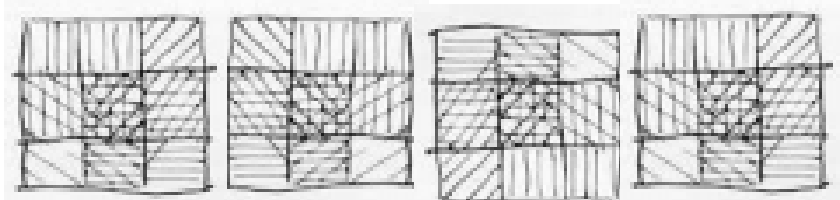

Maria Eugênia Castanho 1

CASTANHO, M.E. University level professors and their pedagogical practice in the healthcare area, Interface Comunic, Saúde, Educ, v.6, n.10, p.51-62, 2002.

For this study, we heard university level professors on the subject of their daily pedagogical practices, with a view to finding possible distinctive features in their teaching. Relying of the thematic oral history methodology, we interviewed eleven professors, coordinators and directors. The interviews were taped and later transcribed, checked, converted into running text and re-written. The results were split into three blocks: on becoming a teacher and on remarkable teachers; on teaching strategies; and on coordinators and directors' duties. The conclusions, also grouped into the three blocks, from which we drew some final inferences, proved to be promising in relation to thinking about initial training and the continued education of professionals from the healthcare area, in connection with the field of university level teaching.

KEY WORDS: Higher education; healthcare education; professional practice.

A pesquisa ouviu professores do ensino superior da área de Saúde sobre sua prática pedagógica cotidiana, visando encontrar eventuais marcas distintivas de sua docência. Usando a metodologia da história oral temática, foram entrevistados onze professores/coordenadores/diretores. As entrevistas foram gravadas e posteriormente transcritas, conferidas, textualizadas e transcriadas. Os resultados foram divididos em três blocos: sobre tornar-se professor e sobre professores marcantes; sobre técnicas de ensino; e sobre a função de coordenador/diretor. As conclusões, também agrupadas nos três blocos de categorias dos quais foram inferidas algumas considerações finais, revelaram-se promissoras para que se pense a formação inicial e continuada dos profissionais da área da Saúde com relação à docência universitária.

PALAVRAS-CHAVE: Ensino superior; Educação em Saúde; prática profissional.

${ }^{1}$ Professora da Faculdade de Educação, Pontifícia Universidade Católica de Campinas/PuCCAMP. <meu@correionet.com.br> 


\section{Introdução}

O presente estudo procura resgatar princípios relevantes para pensar o atual ensino na Área de Saúde e para pensar a formação de professores, trabalhando com a história oral temática de vida de professores da área da Saúde. Esses exercem a docência em uma institução de ensino superior de São Paulo e também atuam como coordenadores de curso e/ou diretores de unidade acadêmica.

A história oral temática ainda é um campo metodológico bastante incipiente na investigação educacional entre nós, diferentemente do que ocorre em outros países, especialmente europeus, que apresentam ampla produção investigativa em torno do tema nas áreas de Psicologia, Sociologia e Ciências da Educação (Montenegro, 1994; Nóvoa, 1995; Kramer et al., 1996). A introdução dessa metodologia no Brasil deu-se na década de setenta, mas só nos anos noventa experimentou expansão significativa. A multiplicação de encontros e a inclusão em programas de pós-graduação de cursos sobre história oral mostram a vitalidade e o dinamismo da área (Ferreira E Amado, 1996). Além disso, a bibliografia atual mostra as possibilidades de incorporação da história oral nas investigações sobre educação (Bogdan \& Biklen, 1997).

As histórias orais temáticas têm cruzado várias disciplinas e recorrido a vários enquadramentos conceituais e metodológicos. Como apontou Nóvoa (1995, p.19) esse tipo de estudo deve "enriquecer-se em termos da ação, caminhando no sentido de uma integração teórica que traduza toda a complexidade das práticas". As vidas de professores podem revelar muito sobre os percursos profissionais, sobre a ligação entre o pessoal e o profissional, os meandros do ato de ensinar (Nóvoa, 1995).

A finalidade da pesquisa assim orientada não é detectar particularismos, mas representações dotadas de generalidade:

\footnotetext{
Estaremos percorrendo representações de caráter universal, onde o ser próprio encontra-se em movimento e em relação com determinações específicas; onde a própria razão de ser se define por algo particular e próprio de aspectos específicos da formação social sem, no entanto, perder seu elo, sua relação com planos gerais/universais (....) O tempo histórico não é o tempo vivido. A história escrita, documentada, distingue-se do acontecido; é uma representação. E nesse hiato entre o vivido e o narrado localiza-se o fazer próprio do historiador. (Montenegro, 1994, p.10)
}

A identidade do professor não é um dado adquirido, mas um lugar de lutas e conflitos, um espaço de construção de maneiras de ser e estar na profissão. A maneira como cada um de nós ensina está dependente daquilo que somos como indivíduos quando exercemos o ensino (Kramer \& Souza, 1996). 


\section{A inovação pedagógica como contexto}

Talvez a palavra mais usada hoje no cenário educacional seja inovação. Palavra polissêmica, usada em discursos conservadores e progressistas, inovação pode referir-se tanto a mudanças periféricas quanto a mudanças profundas nas estruturas do ensino.

Inovação pode ser entendida como processo planejado de desenvolver uma mudança no sistema, cujas possibilidades de ocorrer com freqüência são poucas, mas cujos efeitos representam um real aperfeiçoamento (Goldberg, 1995). Isso implica rejeitar a idéia de que o conceito possa ser identificado apenas com mudança (qualquer mudança). Mudança inovadora (introduzir alguma novidade), mudança progressiva (mudança que implica progresso e aperfeiçoamento: relações entre renovação e aperfeiçoamento), mudança planejada (não ser esporádica) e processo de mudança (seqüência de etapas de novas práticas).

Goldberg (1995) considera que a renovação do sistema deve ser um processo (contínuo e duradouro), mas que precisa ser mais que isso. Distingue entre mudança $e$ inovação, esta última sendo algo mais deliberado, intencional e planificado e não algo que ocorre espontaneamente. Analisa várias conceituações mostrando que, enfim, há diferentes possibilidades de alterar práticas dentro (e apesar) do sistema sócio-econômico e político vigente. O que interessa é discutir a possibilidade de inovação em ambientes acadêmicos específicos.

Cunha (1998), numa pesquisa sobre inovação em Educação, analisou as práticas dos professores e evidenciou que esta aparece em novas formas de conceber as relações entre professor-aluno; teoria-prática; ensino-pesquisa; organização do trabalho em sala de aula; concepção de conhecimento; formas de avaliação; inserção no plano político-social mais amplo; interdisciplinaridade.

Veiga et al. (2000) encontraram características inovadoras nas atividades de ensino, pesquisa e aprendizagem, assim sintetizadas: estão em movimento constante, desenvolvimento histórico e ininterrupto; instigam $e$ propiciam o descobrimento; trabalham com múltiplas tensões presentes na auto-atividade do aluno; favorecem a relação horizontal professor-aluno, permitindo atendimento à singularidade de cada aluno, evitando a homogeneização; asseguram a relação ensino-pesquisa com o trabalho como princípio educativo; são atividades coletivas permeadas por intencionalidade; atribuem à pesquisa importante espaço de mediação entre ensinar $e$ aprender.

Tanto as características apontadas por Cunha (1998) quanto as descritas por Veiga et al. (2000) revelam concepções diferentes das tradicionais, apontando para uma nova forma de ver o conhecimento, a formação profissional e o ensino na universidade.

\section{A pesquisa}

Tendo como contexto a discussão sobre inovação, qualidade e reformulação do ensino, foram realizadas onze entrevistas com professores das áreas de 
Saúde, sendo sete professores/coordenadores de curso e quatro professores/ diretores de unidade acadêmica: Diretor da Faculdade de Odontologia;

Diretor da Faculdade de Ciências Médicas; Diretora da Faculdade de Enfermagem; Diretor do Instituto de Ciências Biológicas e Química; Coordenador do Curso de Odontologia; Coordenadora do Curso de Medicina; Coordenadora do Curso de Nutrição; Coordenadora do Curso de Ciências Farmacêuticas; Coordenador do Curso de Fisioterapia; Coordenadora do Curso de Terapia Ocupacional; Coordenadora do Curso de Ciências Biológicas.

Do total de onze entrevistados, oito são nascidos na década de cinqüenta e três na década de quarenta. Nove estudaram em escolas públicas nos estudos anteriores à universidade, cinco exclusivamente em escola pública $e$ quatro em instituição pública e particular. Dois cursaram só escolas particulares. Quatro são de Campinas, dois da cidade de São Paulo, dois de outras cidades do interior do Estado de São Paulo, dois de outros Estados (Rio de Janeiro e Minas Gerais) e um de outro país (Panamá). Do total, cinco estudaram na Pontifícia Universidade Católica de Campinas/PUCCAMP, quatro na Universidade de São Paulo/USP, um na Universidade Estadual de Campinas/UNICAMP e um na Universidade Federal do Rio de Janeiro/UFRJ. Quanto à titulação há um pós-doutor, dois doutores, três mestres, dois mestrandos, dois especialistas e um com apenas graduação.

Os colaboradores receberam previamente uma folha contendo questões sobre seu ensino a fim de que refletissem sobre o foco que seria desenvolvido na entrevista. Em seguida, foram entrevistados pela autora, com a presença de uma bolsista PIBIC (Programa Institucional de Bolsas de Iniciação Científica). As perguntas foram centradas em torno de algumas categorias básicas, ressaltando que, por categoria entende-se um conceitochave na estrutura significativa de um texto, um conceito do qual dependem ou ao qual se subordinam outros conceitos.

O que significa ser professor no ensino superior na área da Saúde? Como os sujeitos se tornam professores, já que em sua graduação não há, geralmente, disciplinas pedagógicas? Qual a influência de professores marcantes na trajetória profissional? O que estão fazendo como professores e como coordenadores e/ou diretores? O que se usa em termos de técnicas para ensinar? Como pensar a formação de profissionais para o mundo de hoje?

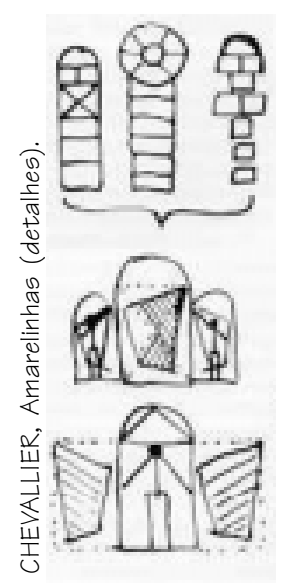

As histórias, textualizadas e transcriadas (Bom Meihy, 1998) revelaram toda a complexidade do que é ser professor na área de Saúde e, ao mesmo tempo, apontaram o que se faz no interior das respectivas aulas, especialmente quanto a técnicas de ensino.

Encontramos na vida dos entrevistados diferenças $e$ semelhanças. Essas diferenças e semelhanças referem-se tanto à entrada para o campo da educação e ao percurso profissional quanto às opiniões que emitiram com relação ao ensino $e$ à aprendizagem. 
As questões apresentadas nas entrevistas foram agrupadas em três grandes blocos, que passam a ser analisados.

Sobre tornar-se professor e sobre professores marcantes

Para a maior parte dos entrevistados, tornar-se professor não foi a opção inicial. Alguns, no entanto, exerceram a monitoria com vistas à carreira acadêmica. Vários relatam que iniciaram a docência por necessidade financeira, por estar desempregado etc. Alguns deram aulas em cursinhos preparatórios ao vestibular, como início de carreira. Há uma colaboradora que afirma ter sido monitora, mas que o fato não foi determinante para o ingresso na docência.

Também aparece com freqüencia a afirmação de que "virou professor de uma hora para outra", embora uma colaboradora tivesse se dedicado pacientemente a descrever que as coisas não se passam assim, envolvendo uma lenta e progressiva construção.

A monitoria aparece geralmente como um degrau (o primeiro) para a docência; inclusive um entrevistado afirmou que não fez monitoria porque não pretendia ser professor e que hoje, como coordenador, orienta seus alunos para esta atividade quando o interesse é por docência.

Aparece também uma causa interessante para explicar o tornar-se professor na área da Saúde: a influência familiar. Houve um entrevistado que apontou de início esse fator, falou de professores marcantes e voltou para a família como a grande variável e maior influência para sua docência. Houve também o caso de um diretor que afirmou várias vezes não ter tido qualquer preparo para dar aulas. Mas acabou por deixar claro, com minúcias, o quanto a avó professora o influenciou e também as freiras em cujas escolas trabalhou lecionando, ainda estudante. O que fica evidente é que não houve preparo sistemático, intencional, mas assistemático, como elemento da cultura que formou o contexto no qual se inseriu.

Vários entrevistados fazem questão de realçar os cursos de formação continuada e outros eventos na área, oferecidos pela instituição, inclusive o mestrado em Educação, que representa contribuição significativa para a práxis pedagógica.

Dignas de registro são as considerações sobre professores marcantes. Há uma lista bastante grande de características nos professores apontados como marcantes. Um colaborador, por exemplo, fala de um professor que marcou como "o bom professor" e outro como o "mau professor". E o que esteve sempre muito claro foi que procuraria seguir o exemplo do bom professor e jamais incorrer no comportamento do mau professor. Uma colaboradora recorda-se da professora que esteve atenta a questões fora da alçada da sala de aula, referentes à formação emocional dos alunos, e que, apesar de "humana" era enérgica no ensino. A entrevistada procura repetir o modelo com seus alunos.

São considerados marcantes: professores que "passavam" o conhecimento mas também davam "dicas" ao aluno que iam além da questão técnica, formando "profissionais inteiros" e não apenas técnicos; professor com experiência e disponibilidade, ensinando o verdadeiro sentido do aprendizado médico-paciente; professor que desenvolveu o hábito de estudar, de procurar, mostrando a responsabilidade pela educação 
continuada; professor com postura "perfeita" sobre a relação médicopaciente - "sob seus conselhos", os grandes princípios foram aprendidos a partir da análise de casuísticas, muito mais do que o currículo oficial exigia. Professora que marcou pelo modo de dar aula, de fazer a parte prática, o conhecimento que tinha e que transmitia; professor que era um "espelho de bom profissional", bom professor, pessoa competente; professor marcante pela atitude de educador, não ensinando apenas a matéria. Marcou por ensinar a postura necessária dentro da vida a qualquer momento. Também a postura física influencia: professora muito elegante, com amor pela matéria que ensinava, "explicava o assunto como se fosse a única coisa bonita que existia no mundo".

Apesar da grande diversidade de características, podem ser ressaltados dois pontos que permeiam todas as lembranças: os professores que marcaram a trajetória de nossos colaboradores eram competentes no domínio da matéria a ser ensinada e aqueles que apresentavam uma postura que extrapolava o próprio domínio específico do conhecimento.

Em resumo, no professor marcante, o profissional e o humano estiveram irremediavelmente entrelaçados. O bom professor é entendido como o educador atento à personalidade complexa do educando, dados que confirmam estudo anterior desenvolvido por Cunha (1989).

\section{Sobre técnicas de ensino}

Podemos dizer que as técnicas utilizadas na área da Saúde baseiam-se, de modo geral, em dois grandes modelos: o das aulas teóricas, em sala de aula, com grande número de alunos presentes, e o das aulas práticas, nos laboratórios, nos ambulatórios, nos mais variados ambientes onde se desenvolvem os estágios e atividades práticas em geral. Esta parte prática exige uma grande carga horária e, segundo uma entrevistada, corresponde à parcela maior de seu curso.

Nas aulas teóricas são usadas aulas expositivas, em vários casos com o apoio de retroprojeção, projeção de slides, apresentação de esquemas $e$ afins. Também a lousa (para fazer desenhos ilustrativos do que está sendo ensinado) é utilizada. Dificilmente são empregadas técnicas de trabalhos em grupo nas classes com número grande de alunos.

Diz um outro entrevistado, que a aula é "o lugar onde o aluno faz correlações" e que "a atitude docente deve ser no sentido de permitir que tais correlações sejam feitas". Também é afirmado que o professor deve ser "um agente para despertar curiosidade". Considera-se que faz diferença usar uma técnica ou outra, mas que o emprego diferencial depende mais do número de alunos do que da estratégia docente. Nas falas dos entrevistados, "a aula expositiva é usada para turmas grandes", "se os alunos provêm de um bom colegial, a maioria das aulas é expositiva e se provêm de um colegial mais deficitário, se o perfil do aluno é diferente, se o aluno trabalha, a leitura é feita em sala de aula e é indicado um livro texto básico".

Um entrevistado mostrou a relação íntima que vê entre técnicas de ensino, processo educativo e avaliação, enfatizando que quer mudar seus mecanismos de verificação da aprendizagem. Poucos entrevistados falaram da importância do ensino com pesquisa (proposta discutida por Paoli, 1991; 


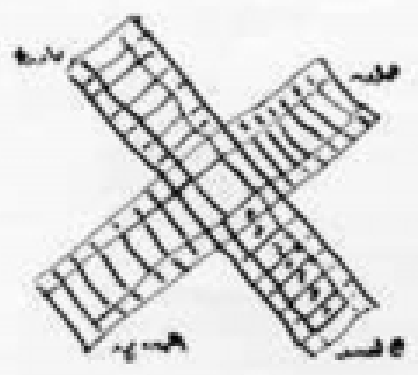

Cunha, 1992 e 1995). Também foi apontado que a prática deve estar presente desde o primeiro ano dos estudos superiores.

A aula expositiva com retroprojeção para "apoiar o professor" é usada com relativa freqüência. Vários entrevistados usavam apostilas próprias para seu ensino e aboliram-nas por considerarem importante que o aluno vá aos livros. Alguns disseram que "a recente avaliação institucional que ouviu os alunos" apontou que há pouca indicação de leituras extra-classe. Estão "corrigindo isso", segundo seu depoimento.

Foi possível notar muita abertura e sinceridade de parte dos entrevistados. Um deles chegou a afirmar que "sofre-se por não ter didática, estar diante do aluno e não ter didática". Também preocupam-se com o simplismo da avaliação que é feita, mas declaram ter dificuldades teóricas e práticas para alterá-la. Uma entrevistada declarou que chega a corrigir novecentas provas por bimestre!

A técnica do seminário recebe opiniões opostas: há quem afirme que não a usa porque nela "não vê qualquer utilidade", "qualquer ponto positivo", $e$ há quem a utilize. Há, outrossim, formas diferentes de empregá-la. Um colaborador, por exemplo, afirma que faz o seminário em duplas, que os dois responsáveis devem vir preparados pois "nunca sabem qual irá falar". Assim, ambos estudam. Não houve maiores explicações sobre o valor intelectual e pedagógico da técnica. Também foi apontado que é importante o docente preocupar-se com a integração vertical e horizontal de sua disciplina na estrutura curricular.

A questão da integração no ensino na área de saúde entre a parte básica e a profissionalizante apareceu em vários depoimentos. As observações a esse respeito são bastante variadas: alguns consideram "muito difícil" promover tal integração, outros enxergam várias alternativas para a implementar, enquanto um colaborador considera "extremamente simples a solução". Reporta-se ao Hospital Sara Kubitschek, em Brasília, onde o estudante, "examinando o paciente na companhia de seu professor, desce para o subsolo para ver um coração, por exemplo, no laboratório de Anatomia, se apresentar dúvidas". Avalia que isso pode ser feito sem maiores problemas, sem necessidade de mudanças curriculares.

\section{Sobre a função de Coordenador/Diretor}

Variadas são as ações desenvolvidas ou em implantação em cada unidade e em cada curso estudado com relação à ação de seus dirigentes. Há um movimento de revisão ampla do currículo com maior ou menor intensidade, aqui e ali, com resistências explícitas ou veladas. Há coordenador interessado em que "os docentes se atualizem", estimulando a educação continuada, incentivando cursarem mestrado "para formarem-se, não só no aspecto técnico". Há os preocupados em usar o espaço das reuniões do departamento para discussões pedagógicas, "para crescimento"; ou, ainda, para rever os planos e ementas, exigindo "pontualidade na entrega" e pondo o representante de classe para "cobrar" do professor, conclamando-o para ser o vínculo com a coordenação. Outras questões apontadas: "elaboração e entrega dos planos de curso", "horário dos professores", "acerto da situação de alunos do diurno e do noturno". Há também reuniões setoriais para 
articular programas afins.

Há coordenador interessado em dar ao curso uma "cara nova", considerando que os alunos devam ser "nivelados por cima" e que os professores tenham "compromisso efetivo com seus discípulos". Insiste-se na busca de maior correlação entre teoria e prática e em aliar o ensino com a pesquisa. Este aspecto, embora presente, apareceu pouco no conjunto das entrevistas. Também há interesse em "conscientizar o corpo docente a respeito do papel da educação". Há preocupação em "mudar muita coisa no estágio", "que é onde está a carga maior". Com relação ao planejamento, fala-se "em sair do papel para ser efetivado na realidade".

Há posições teóricas mais elaboradas como a do entrevistado que considera o projeto pedagógico como um empreendimento coletivo, baseado na perspectiva "do profissional que se quer formar". A preocupação é dar uma boa formação técnica "e sobretudo formar um bom profissional, com conhecimento, capacidade de reflexão, de propor coisas, transformar".

Há também o entrevistado que declara ter como preocupação "levar ao departamento e socializar com os colegas o enfoque ser professor". Procurar

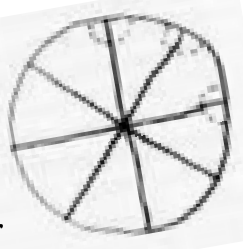
mecanismos para "melhorar a didática dos docentes". Outros apontam, ainda, que é necessário ao docente ficar no mínimo vinte horas na instituição, ainda que sejam dez horas assistenciais e dez horas de docência. $E$, por fim, que é importante o docente ser titulado e estar sempre envolvido com educação continuada.

Observam-se mudanças "intuitivas", sem fundamentação teórica para melhorar o ensino, procurando levar o aluno à participação, aos trabalhos em grupo, "quando possível". Nessa "busca intuitiva" por mudanças, percebe-se hesitação dos sujeitos. Um deles declarou: "não sei se estou orientando corretamente". Há também, embora tímida, uma certa preocupação interdisciplinar por parte de um ou outro docente, com o planejamento de atividades conjuntas da sua disciplina com outra.

Discussão e desafios

O conjunto de questões que o material oferece é amplo e permite uma série de considerações de interesse acadêmico e prático.

Com relação ao primeiro bloco de categorias - Sobre tornar-se professor e sobre professores marcantes - a contribuição mais completa veio de uma entrevistada que fez questão de frisar que não se "vira" professor de uma hora para outra e que, na verdade, se constrói o ser professor. Baseando-se nos estudos de Psicologia Social de Moreno, argumenta que essa construção dá-se basicamente em três fases: role taking (tomar o papel de um modelo de professor), role playing (brinca-se com o modelo, pela desenvoltura em dominá-lo) e role creative (cria-se a partir das fases anteriores). São etapas com duração variada, cada uma delas dependendo de diversas variáveis como maturidade, conhecimento e aprendizagem, efetivação da ação. De fato, ser professor é um processo complexo que necessita de tempo. "Um tempo para refazer identidades, para acomodar inovações, para assimilar mudanças" (Nóvoa, 1995, p.16).

No tocante a professores marcantes, pode-se notar que a postura, a 
atitude de educador, não ensinando apenas o conteúdo específico, mas, também, atitudes diante da vida, é o que se destaca como mais forte nos depoimentos. É bem verdade que também aparecem testemunhos apontando professores muito bons pelo grau de competência e exigência com que ensinavam suas disciplinas. Mas o que chama a atenção é que os depoimentos mais fortes referem-se àqueles que, além de terem um domínio muito grande do específico, têm reservas humanas admiráveis. $O$ que nos remete aos estudos de Nóvoa (1995, p.15) quando afirma que "o professor é a pessoa e uma parte importante da pessoa é o professor".

Com relação ao segundo bloco de categorias - Sobre técnicas de ensino podemos perceber que várias técnicas são usadas, mas que este não é o ponto realmente importante, se discutido isoladamente.

Não foi rara, quando se discutiu o tema das técnicas, a menção a questões ligadas ao currículo. E apareceu, com freqüência, a discussão sobre (des)integração básico/profissionalizante. Ainda se trata de um ponto não resolvido, embora tenham sido detectadas várias ações no sentido de encaminhar soluções. Alguns entrevistados parecem tender a uma formação mais especializada, outros para uma mais generalista. A referência aos parâmetros curriculares do MEC é freqüente e a sinalização é para a formação generalista exigida pelos tempos neoliberais. O que certamente revela uma inversão no que até pouco tempo era indicado: em uma sociedade em processo de mudança acelerada, a formação generalista parece ser mais conveniente, pois, teoricamente, leva a uma maior flexibilidade na escala das ocupações.

Alguns equívocos pedagógicos podem ser notados. Um exemplo é considerar que o conhecimento é somatória e, sendo assim, os alunos devem ler "muitos livros para memorizar, para guardar", quando a memorização deve ser compreendida como subproduto de um trabalho de construção intelectual. Vários entrevistados falam da importância de ler obras reputadas na área e vêm substituindo as apostilas por livros. Também notase incidência na idéia de que o aluno deva exibir ao professor a memorização $e$ a reprodução de informações. Inclusive foi dito que "cobrar é entre aspas, querer saber o retorno". Também foi observada preocupação com o conceito estreito de mercado, pensando que "é preciso olhar sempre o que o mercado está pedindo".

Uma das questões mais sérias de caráter macroestrutural é a reflexão sobre o que o mercado está pedindo à universidade.

É comum afirmar que o ensino de graduação deve profissionalizar para o mercado. Não é raro exemplificar-se com o modelo americano. Mas convém lembrar que o sistema universitário americano tem três grandes modalidades: universidades de pesquisa, universidades de ensino e colleges ou pós-secundários profissionalizantes - espaço acadêmico espremido entre o terceiro ano do segundo grau e o mundo universitário. A função primordial dos colleges é formar mão-de-obra para atender às exigências operacionais imediatas do mercado, em especial do setor técnico e produtivo (Ristoff, 1999). Em nosso caso, ao defender a profissionalização, poder-se-ia falar num reducionismo perigoso de todo o ensino superior, preparando para o mercado. 
Ademais, é sombrio pensar que a educação esteja em função, não da sociedade ou do interesse público, mas do "mercado", lugar onde se vendem competências e se compram aptidões.

No terceiro bloco de categorias - Sobre a função de coordenador/diretor apesar da diversidade de opiniões e de aspectos considerados, chama a atenção que alguns têm preocupações mais amplas, reportando-se ao projeto do curso e outros pontos de caráter macro, enquanto outros vêm se dedicando a questões mais pontuais e ligadas a aspectos técnicos do processo, de natureza microestrutural, sem conseguir perceber que ambas as dimensões estivessem articuladas em todos os cursos.

Muitos se reportam aos cursos esporádicos oferecidos pela instituição como importantes momentos de reflexão e formação pedagógica e também à avaliação institucional ora em curso como importante momento para dar indicações e sinalizações sobre o processo de ensino e aprendizagem. Referemse especialmente à indicação de bibliografia complementar, que os alunos dizem ser deficiente e que procuram corrigir.

Oferecer educação continuada parece ser um dos pontos mais valorizados pelos entrevistados, tendo os cursos funcionado "como um alento, como se fosse uma luz que se abria".

Nas entrevistas de nossos colaboradores, a inovação aparece de maneira tênue, não constituindo marca definidora da prática pedagógica desses docentes. Trata-se de um desafio a ser vencido no ensino na área de Saúde, ao menos na realidade investigada.

Podemos afirmar que, mesmo em tempos de racionalização, de uniformização, de globalização e mercantilização, cada docente continua a produzir no mais íntimo de si mesmo a sua própria maneira de ser professor. Produção cada vez mais exigente apontando para a necessária atualização dos saberes ensinados em educação continuada.

Não podemos prescindir de formação pedagógica para o exercício do magistério superior. Pelo contrário, é indispensável e urgente a necessidade da discussão de como introduzir, na formação inicial e continuada dos profissionais da área da Saúde em nível superior, a competência pedagógica requerida para aulas de qualidade junto a jovens que buscam o ensino superior, introduzindo inovações que atinjam as estruturas profundas do ensino.

\section{Referências}

BOGDAN, R., BIKLEN, S. Investigação qualitativa em educação. Porto: Porto Editora, 1997. BOM MEIHY, J.C.S. Manual de história oral. 2.ed. São Paulo: Loyola, 1998.

CASTANHO, S., CASTANHO, M.E. (Orgs.) O que há de novo na educação superior. Campinas: Papirus, 2000.

CUNHA, M.I. O professor universitário na transição de paradigmas. Araraquara: JM, 1998.

CUNHA, M.I. O bom professor e sua prática. Campinas: Papirus, 1999.

FERREIRA, M.M., AMADO, J. (Orgs.) Usos \& abusos da história oral. Rio de Janeiro: Editora da Fundação Getúlio Vargas, 1996.

GOLDBERG, M.A.A. Inovação educacional: a saga de sua definição. In: GARCIA, W.E. (Org.)

Inovação educacional no Brasil: problemas e perspectivas. 3.ed. Campinas: Autores 
PROFESSORES DE ENSINO SUPERIOR DA ÁREA DE SAÚDE...

Associados, 1995. p.197-209.

KRAMER, S., JOBIM, S., SAUZA, S. (Orgs.) Histórias de professores. São Paulo: Ática, 1996.

MONTENEGRO, A.T. História oral e memória: a cultura popular revisitada. 3.ed. São Paulo:

Contexto, 1994.

NÓVOA, A. (Org.). Vidas de professores. 2.ed. Porto: Porto Editora, 1995.

PAOLI, N.J. Para repensar a universidade e a pós-graduação. Campinas: Ed. da Unicamp, 1985.

RISTOFF, D. Boyer Comission: o modelo americano em debate. In: TRINDADE, H. (Org.)

Universidade em ruínas na república dos professores. Petrópolis: Vozes, 1999. p.75-

86.

TRINDADE, H. (Org.) Universidade em ruínas na república dos professores. Petrópolis:

Vozes, 1999.

VEIGA, I.P.A., RESENDE, L.M.G., FONSECA, M. Aula universitária e inovação. In: VEIGA, I.P.A.,

CASTANHO, M.E. (Orgs.) Pedagogia universitária: a aula em foco. Campinas: Papirus,

2000. p.161-191.

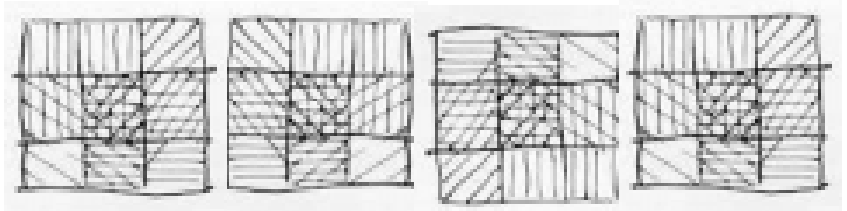

CASTANHO, M. E. L. M. Profesores de enseñanza superior del área de salud y su práctica pedagógica, Interface - Comunic, Saúde, Educ, v.6, n.10, p.51-62, 2002.

La pesquisa escuchó profesores de enseñanza superior del área de salud sobre su práctica pedagógica, con el objetivo de encontrar eventuales marcas distintivas de su docencia. Usando la metodología de la historia oral temática, fueron entrevistados once profesores/ coordinadores/directores a través de grabaciones, posteriormente transcritas, conferidas, textualizadas y transcreadas. Los resultados fueron divididos en tres bloques, a saber: sobre hacerse profesor y sobre profesores sobresalientes; sobre técnicas de enseñanza y sobre la función de coordinador/director. Las conclusiones, también agrupadas en los tres bloques de categorías de los cuales fueron inferidas algunas consideraciones finales, se revelaron promisorias para que se piense la formación inicial y continuada de los profesionales del área de salud con relación a la docencia universitaria.

PALABRAS CLAVE: Enseñanza superior, educación en área de salud; práctica pedagógica. 